\title{
Variation of black carbon in Northeast China based on ground observation and MERRA-2 reanalysis data
}

\author{
Qingli Song ${ }^{l}$, Yanan $\mathrm{Li}^{2, *}$,Dajiang $\mathrm{Yu}^{l}$, Jinrong Zhao ${ }^{l}$ and Zhou $\mathrm{Li}^{3}$, Yong Zhang ${ }^{2}$ \\ ${ }^{1}$ Longfengshan Atmospheric Background National Observation and Research Station, Heilongjiang, China, 150200 \\ ${ }^{2}$ Meteorological Observation Center, China Meteorological Administration, Beijing, China, 100081 \\ ${ }^{3}$ Diqing Meteorological Bureau, Yunnan, China, 177499
}

\begin{abstract}
The temporal variations of black carbon concentration at 7 sites, including Longfengshan, Anshan, Benxi, Dalian, Changchun, Shenyang, and Fushun, in Northeast China was studied based on up to 11 years of ground observations and MERRA-2 reanalysis dataset. Except for Benxi, Changchun and Shenyang, at other four sites, the ground-based black carbon concentrations have decreased generally in the last decade, while changes in the black carbon concentration of MERRA-2 are relatively small. The seasonality of measured black carbon concentration shows a trend of low in May-June and high in January at all sites, and the diurnal cycles present similar pattern with two peaks occurring at 10:00-12:00 UTC and 23:00-24:00 UTC respectively, two troughs occurring at 05:00-07:00 UTC and 19:00-20:00 UTC respectively. The daily mean of MERRA-2 black carbon concentration is $49.3 \%$ lower than that of the ground observations at 7 sites averagely. They also show poor consistency in terms of seasonal and daily changes, which perhaps means an inappropriate application of MERRA-2 black carbon concentration at single point in Northeast China.
\end{abstract}

\section{Introduction}

As black carbon (BC) aerosol can absorb solar radiation, it has become the second key agent only behind $\mathrm{CO} 2$ for the global warming ${ }^{[1]}$. Ambient $\mathrm{BC}$ observations have been conducted intensively all over the world ${ }^{[2-4]}$. China is considered as an important area for $\mathrm{BC}$ emission because of the rapid economic growth ${ }^{[5]}$. Since 2005, the China Meteorological Administration has begun to launch $\mathrm{BC}$ operational observations across the country, and gradually established the China $\mathrm{BC}$ Observational Network (CBNET) ${ }^{[6]}$, based on the CNNET, lots of studies have been conducted ${ }^{[7-9]}$. However, the concentration and optical properties of $\mathrm{BC}$ are highly geographically dependent, to find properties of $\mathrm{BC}$ in various regions is essential to understand the role of $\mathrm{BC}$ on climate.

Then, a problem appeared, that was the distribution of ground-based sites was not dense enough to study the aerosol properties at a high spatial resolution scale. Therefore, scientists came up with the ideas of using model simulations ${ }^{[10]}$, satellite observation and reanalysis data to analyze the temporal-spatial distribution ${ }^{[11-12]}$, physical and chemical properties, and radiation effects of black carbon within a uniformly distributed range. Among these three methods, reanalysis data is a makeup and comprehensive application of the other two methods, it combines data of different sources with numerical weather prediction products for optimal integrations, like the aerosol diagnostic fields of Modern-Era
Retrospective Analysis for Research and Applications, version 2 (MERRA-2) ${ }^{[13]}$. The MERRA-2 aerosol diagnostic fields have been widely used since release, MERRA-2 AOD validation and analysis in the Yangtze River Delta in eastern China have been carried out, obtaining a good agreement between MERRA-2 AOD and sky radiometer and MODIS AOD ${ }^{[14]}$. The spatialtemporal distributions of $\mathrm{BC}$ concentration and $\mathrm{BC}$ column mass density in East China have been investigated with MERRA-2 products ${ }^{[15]}$.

There are currently no studies on long-term variation of $\mathrm{BC}$ concentration based on ground observations, and no comparisons to MERRA-2 BC data in the Northeast China now. In this paper, a up to 11 years measurements of $\mathrm{BC}$ concentration and MERRA-2 BC surface mass concentration at 7 sites in Northeast China is presented.

\section{Data description}

The Aethalometer instruments (Model AE-31, Magee Scientific Inc.) were used to measure black carbon concentration continuously at 7 sites of the CBNET as shown in Fig. 1. This kind of instrument is a good choice for measuring optical transmission at 7 wavelengths (370, $470,520,590,660,880$, and $950 \mathrm{~nm}$ ) through a quartz filter tape on which the ambient particles are forced to impinge before the commercialization of Model AE33 Aethalometer ${ }^{[16]}$. Since the strong light absorption of black carbon at the near infrared channel[ ${ }^{[17-18]}$, the 880 $\mathrm{nm}$ wavelength was considered as the standard channel

\footnotetext{
* Corresponding author: yananli22808@163.com
} 
for measuring black carbon. The time span of the ground-based BC observations and the amount of all daily averages used in this study are displayed in Table 1.



Fig. 1. Locations of 7 ground observation sites (Longfengshan is a regional atmospheric background site, and Dalian is a coastal urban site).

Table 1. Time span of the black carbon observations at 7 sites.

\begin{tabular}{|c|c|c|}
\hline Site Name & Time Span & $\begin{array}{c}\text { Daily Average } \\
\text { Amount }\end{array}$ \\
\hline Longfengshan & $2007-2017$ & 3358 \\
\hline Anshan & $2007-2017$ & 3539 \\
\hline Changchun & $2012-2017$ & 836 \\
\hline Shenyang & $2007-2017$ & 3232 \\
\hline Benxi & $2007-2017$ & 3642 \\
\hline Fushun & $2007-2017$ & 3578 \\
\hline Dalian & $2007-2015$ & 3158 \\
\hline
\end{tabular}

The MERRA-2 dataset of a $0.625^{\circ} \times 0.5^{\circ}$ longitudeby-latitude resolution is the latest reanalysis data produced by Global Modeling and Assimilation Office (GMAO) ${ }^{[19]}$. There are many kinds of aerosol products in MERRA-2, the BC surface mass concentration is merely focused in this study. As a grid of MERRA-2 is large enough to cover a ground site in space, the grid value geographically closet to a site is selected as the comparison object to the observation in this site.

\section{Results and analysis}

\subsection{Yearly variations of BC concentration}

Fig. 2 shows the yearly variations of annual average BC concentration at 7 sites, including a regional atmospheric background site, a coastal urban site, and five inland urban sites, in Northeast China. From 2007 to 2017, at Longfengshan (LFS) and Anshan site, the annual average $\mathrm{BC}$ concentration increased for the first 1-2 years, then began to fall and kept falling to 2016, and increased slightly in 2017. At Dalian, Benxi and Shenyang site, the annual average BC concentration decreased firstly, and then continued to increase for two years, and finally started to decline again. At Fushun site, the annual average $\mathrm{BC}$ concentration basically showed a downward trend during 2011-2017. It should be noted that there's a short span of BC concentration at Changchun site and its trend cannot be judged. Compared with the changes of observed $\mathrm{BC}$ concentration in the last decade, MERRA-2 BC concentration is relatively stable. Due to the Chinese environmental protection and emission reduction control in recent years, the observed $\mathrm{BC}$ concentration become less than the MERRA-2 BC concentration at Anshan and Fushun site in 2017, at Dalian site in 2015.

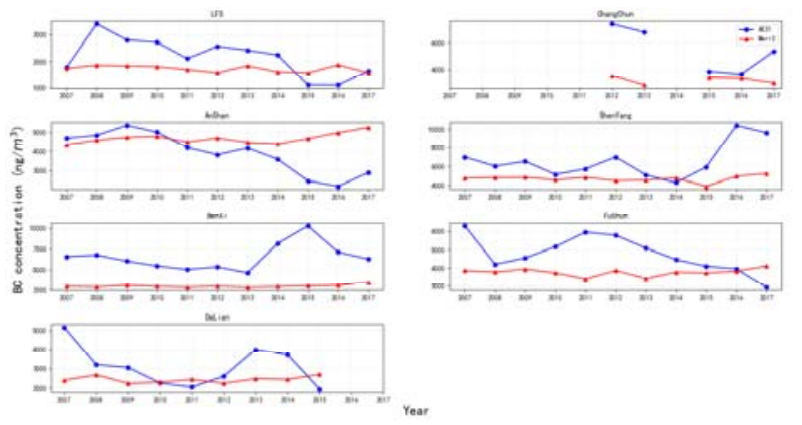

Fig. 2. Time series of annual mean $B C$ concentration based on ground observations (denoted by AE31 in the figure) and MERRA-2 BC at 7 sites.

Based on the data shown in Table 1, the average annual observed $\mathrm{BC}$ concentration at LFS is the lowest with $2169 \pm 715 \mathrm{ng} / \mathrm{m}^{3}$, followed by Dalian with $3103 \pm 1047 \mathrm{ng} / \mathrm{m}^{3}$. The average annual observed BC concentration in Changchun, Anshan, Shenyang, Benxi, and Fushun are $5407 \pm 1695 \mathrm{ng} / \mathrm{m}^{3}, 3920 \pm 1046 \mathrm{ng} / \mathrm{m}^{3}$, $6600 \pm 1869 \mathrm{ng} / \mathrm{m}^{3}, 6505 \pm 1613 \mathrm{ng} / \mathrm{m}^{3}$, and $4762 \pm 1001$ $\mathrm{ng} / \mathrm{m}^{3}$, respectively. From the differences of the $\mathrm{BC}$ concentration at 7 sites, the representative of LFS as the low background point can also be reflected in the Northeast China.

\subsection{Validation of MERRA-2 black carbon surface mass concentration}

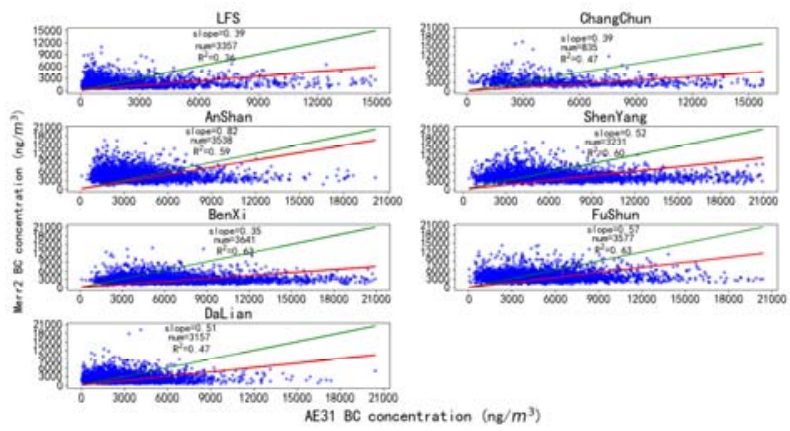

Fig. 3. Scatter plot of daily average $\mathrm{BC}$ concentration between MERRA-2 and ground observations (denoted by AE31 in the figure) at 7 sites .

In Fig.3, comparisons of daily average observed BC concentration and MERRA-2 BC concentration at 7 sites were presented. Observed $\mathrm{BC}$ concentration and MERRA-2 BC concentration at 7 sites are poorly correlated $\left(R^{2}=0.36-0.63\right)$. MERRA-2 BC concentration were largely underestimated at Benxi, LFS and Changchun site by $61 \%-65 \%$, the best agreement 
between MERRA-2 and observed BC concentration is seen at Anshan site (the slope and $R^{2}$ are 0.82 and 0.59 , respectively). Compared with the $\mathrm{BC}$ concentration at the ground observation sites, the $\mathrm{BC}$ concentration of MERRA-2 is underestimated by a percent of $49.3 \%$ averagely.

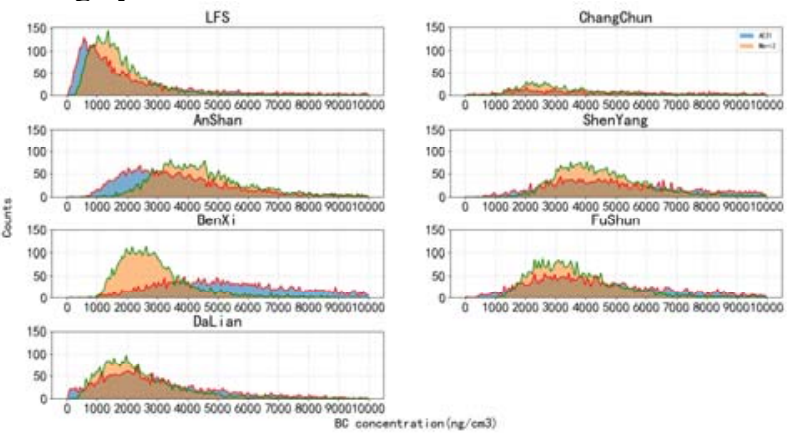

Fig. 4. Frequency distribution of daily average observed $\mathrm{BC}$ concentration (denoted by AE31 in the figure) and MERRA-2 BC concentration at 7 sites.

In order to study the reasons for the inconsistency at 7 sites, the frequency distribution of the daily measured and MERRA-2 BC concentrations was analyzed as shown in Fig. 4. Both kinds of BC concentration at each site shows a lognormal distribution. Obviously, at LFS and Anshan site, the mode values of observed BC concentration are smaller than that of MERRA-2. At Benxi and Dalian site, the mode values of the observed BC concentration are larger than that of MERRA-2. In the other three sites, the corresponding mode values of the observed and MERRA-2 BC concentratons are close, but the maximum frequency differences are large. The poor consistency of observed and MERRA-2 BC concentration in the scatter plots inevitably results from their different $\mathrm{BC}$ concentration frequency distributions at 7 sites.

\subsection{Monthly BC concentration}

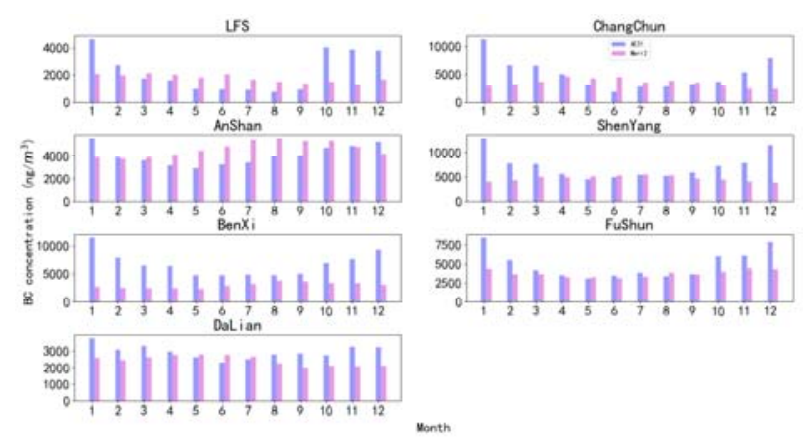

Fig. 5. Monthly variation of observed $B C$ concentration (denoted by AE31 in the figure) and MERRA-2 BC concentration at 7 sites.

Fig. 5 presents monthly variations of observed and MERRA-2 BC concentration at 7 sites. According to the ground observations, the monthly average $\mathrm{BC}$ concentration at 7 sites have obvious seasonal change and similar trend, BC concentrations are highest in January and lowest in May-June. The seasonal change in $\mathrm{BC}$ concentration is closely related to changes in local emissions and meteorological conditions. On one hand, due to the low temperature in winter in Northeast China, resident heating usually starts in late October and ends in early April of the following year, regardless of the changes in motor vehicle emissions and industrial emissions, residential heating and biomass burning in winter leads to increased $\mathrm{BC}$ emission ${ }^{[20]}$. On the other hand, under the control of a stable high-pressure weather system in Northeast China in winter, an inversion layer is likely to appear in the lower atmosphere, which is not conducive to aerosol diffusion, leading to an increase in the observed BC concentration. The January is usually the coldest month in Northeast China ${ }^{[21]}$, meaning the more coal burning and $\mathrm{BC}$ emission. In the summer months in Northeast China, lack of BC emissions from coal burning for residential heating and significant precipitation increasing accelerat the wet deposition of aerosols ${ }^{[11]}$, in addition, increasing in temperature and boundary layer height enhance the diffusion of $\mathrm{BC}$, leading to the lowest observed $\mathrm{BC}$ concentration. This variation of seasonal $\mathrm{BC}$ loadings, namely low in summer months and high in winter months, is similar to the state of Tongyu site, which is also located in northeastern China.

Only at Fushun site, the monthly variation of MERRA-2 and observed $\mathrm{BC}$ concentration is relatively similar. At other sites, the monthly variations of MERRA-2 BC concentration show a completely different pattern from the ground observation. At Anshan and Benxi site, the BC concentration of MERRA-2 is highest in early autumn. At LFS, Dalian and Changchun site, the BC concentration of MERRA-2 is highest in late spring, while at Shenyang, the concentration is highest in summer, and MERRA-2 BC concentration is relatively close to the ground observation. This difference may be associated with the emission source data used by MERRA-2. Biomass burning emission in MERRA-2 is from the NASA Quick Fire Emission Dataset (QFED) version 2.1, which is a global fire radiative power based inventory of daily emissions of aerosol precursors and trace gases $^{[22]}$. A series of complex physical and chemical processes from aerosol precursors to black carbon aerosols, as well as the uncertainties in the calculation process, may cause the difference between MERRA-2 BC concentration and ground observed BC concentration.

\subsection{Diurnal variation of $\mathrm{BC}$ concentration}

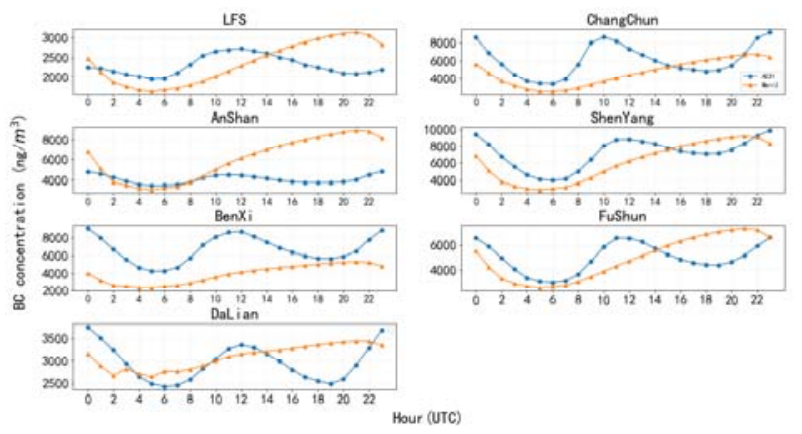

Fig. 6. Diurnal variation of observed $B C$ concentration (denoted by AE31 in the figure) and MERRA-2 BC concentration at 7 sites. 
As displayed in Fig. 6, the diurnal variation of ground-based BC concentration has obvious bimodal characteristics. The two peaks appear at 10:00-12:00 UTC and 23:00-24:00 UTC respectively, while the two troughs appear at 05:00-07:00 UTC and 19:00-20:00 UTC respectively. The appearance of the two peaks is related to the morning and evening peak traffic emissions, and the appearance of the two troughs is usually related to the diffusion and uplift of the boundary layer at noon and early morning ${ }^{[23]}$. Gao et al. (2009) and Wang et al. (2011) also indicated the similar diurnal variations based on measurements with AE31 instruments in Northeast China ${ }^{[8-9]}$.

The diurnal variation of MERRA-2 BC concentration showed completely different characteristics at 7 sites, it is a single peak and single trough type. The trough value occurs at 05:00-07:00 UTC, at when the first trough value of the ground-based BC observation appears. The appearance time of the peak value corresponds to the second valley value of the ground-based $\mathrm{BC}$ observation. The huge differences in the daily variation of $\mathrm{BC}$ concentration obtained by two different kinds of data remind us that MERRA-2 black carbon concentration is perhaps not suitable for analysis of a single point.

\section{Conclusion}

Surface black carbon concentration in different timescales at 7 sites in Northeast China were studied based on up to 11 years of ground observations and MERRA-2 reanalysis dataset. At LFS, Anshan, Dalian, and Fushun sites, the measured $\mathrm{BC}$ concentration have decreased generally in a decade scale, while an opposite trend emerged at Benxi and Shenyang site. In 2017, a transformation is basically realized, that is the higher measured concentration becoming a lower comparing to MERRA-2 BC concentration at Anshan and Fushun site. In sharp contrast, the MERRA-2 BC concentration is relatively stable during 2007-2017. The monthly variations of measured $\mathrm{BC}$ concentration show a trend of low in May-June due to the strong precipitation, reduced coal burning emissions and enhanced boundary layer mixing, and high in January due to more residential heating emissions and weak aerosol diffusion at all sites. Diurnal cycles of ground observed BC concentration present similar pattern with two peaks occurring at 10:00-12:00 UTC and 23:00-24:00 UTC respectively, two troughs occurring at 05:00-07:00 UTC and 19:0020:00 UTC respectively. Frequency distribution and scatter plots of daily averages of observed and MERRA$2 \mathrm{BC}$ concentration were also studied to validate the MERRA-2 BC concentration, but poor correlation exists between them. They also show poor consistency in terms of seasonal and daily changes, which probably means an inappropriate application of MERRA-2 black carbon concentration at single points in Northeast China.

Finally, it must be mentioned that discovering the differences between the characters of observed and MERRA-2 BC concentration is not the ultimate goal of this research, but finding the reasons for the differences and improving it is what we need to do in the future.
And we believe that "The more we study it, the more mechanisms people find".

\section{Acknowledgment}

This work was supported by the Ministry of Science and Technology of China under project No. 2017YFC1501802, the National Nature Science Foundation of China under project No. 91644223. The authors appreciate the NASA Global Modelling and Assimilation Office for providing the MERRA-2 data online.

\section{References}

1. Bond T. C., S. J. Doherty, D. W. Fahey, P. M. Forster, T. Berntsen, B. J. DeAngelo. Bounding the role of black carbon in the climate system: a scientific assessment. J. Geophys. Res. Atmos. 118, 5380-5552 (2013)

2. Gao X., Cao X., Tian P., Zhang L., Huang Z., Zhou T. Combined observation of a dust storm over the Loess Plateau using a dual-wavelength lidar and an aethalometer. Atmos. Pollut. Res. 8(6):1103-1112 (2017)

3. Huang J., Fu Q., Zhang W., Wang X., Zhang R., Ye H., Warren SG. Dust and black carbon in seasonal snow across Northern China. Bull. Am. Meteorol. Soc. 92:175-181 (2010)

4. Putero D., Cristofanelli P., Marinoni A., Adhikary B., Duchi R., Shrestha SD et al.. Seasonal variation of ozone and black carbon observed at Paknajol, an urban site in the Kathmandu Valley, Nepal. Atmos. Chem. Phys. 15:22527-22566(2015)

5. Qin, Y., Xie, S.. Spatial and temporal variation of anthropogenic black carbon emissions in China for the period 1980-2009. Atmos. Chem. Phys. 12, 4825-4841 (2012)

6. Zhang Y., Y. Li, J. Guo, Y. Wang, D. Chen, H. Chen. The climatology and trend of black carbon in China from 12 year ground observation, Climate Dyn. 53, 5881-5892 (2019)

7. B. Guo, Y.Q. Wang, X.Y. Zhang, H.Z. Che, J. Ming, Z.W. Yi. Long-Term variation of Black Carbon Aerosol in China Based on Revised Aethalometer Monitoring Data. Atmosphere, 11, 684 (2020)

8. Gao Z., R. Zhang, L. Su. Characteristic analysis of atmospheric black carbon aerosols in Changchun in autumn and winter. Plateau Meteorology. 4, 803807 (2009)

9. Wang Y., Y. Ma, Z. Lu, D. Zhou, N. Liu, Y. Zhang, Y. Hong. In situ continuous observation of atmospheric black carbon aerosol mass concentration in Liaoning region. Reserch of Envornmental Sciences. 24(10) : 1088-1096 (2011)

10. Wang Y, Ma PL, Peng J, Zhang R, Jiang JH, Easter $\mathrm{RC}$, Yung YL Constraining aging processes of black carbon in the community atmosphere model using 
environmental chamber measurements. J Adv Model Earth Syst 10:2514-2526 (2018)

11. Cheng, T., Z. Han, R. Zhang, H. Du, X. Jia, J. Wang, and J. Yao. Black carbon in a continental semi-arid area of Northeast China and its possible sources of fire emission, J. Geophys. Res., 115, D23204 (2010)

12. Qin, W., Zhang, Y., Chen, J., Yu, Q., Cheng, S., Li, W., Liu, X., Tian, H.. Variation, sources and historical trend of black carbon in Beijing, China based on ground observation and MERRA-2 reanalysis data. Environ. Pollut. 245,853-863 (2019)

13. Randles C., A. Da Silva, V. Buchard, P. Colarco, A. Darmenov, R. Gocindaraju, A. Smirnov, B. Holben, R. Ferrare, J. Hair. The MERRA-2 aerosols reanalysis, 1980 onward. Part I: system description and data assimilation evaluation. J. Clim. 30, 68236850 (2017)

14. Sun E., X. Xu, H. Che, Z. Tang, K. Gui, L. An, C. $\mathrm{Lu}, \mathrm{G}$. Shi. Variation in MERRA-2 aerosol optical depth and absorption aerosol optical depth over China from 1980 to 2017. J. Atmos. Sol.-Terr. Phy. 186, 8-19 (2019)

15. Xu X., X. Yang, B. Zhu,Z. Tang, H. Wu, L. Xie. Characteristics of MERRA-2 black carbon variation in east China during 2000-2016. Atmos. Environ. 222, (2020)

16. Sharma MC, Pandey VK, Kumar R, Latief SU, Chakrawarthy E, Acharya P. Seasonal characteristics of black carbon aerosol mass concentrations and influence of meteorology, New Delhi (India). Urban Clim 24:968-981(2018)

17. Weingartner, E., H. Saathoff, M. Schnaiter, N. Streit, B. Bitnar, and U. Baltensperger. Absorption of light by soot particles: determination of the absorption coefficient by means of aethalometers, J. Aerosol Sci., 34, 1445-1463 (2003)

18. Favez, O., S. C. Alfaro, J. Sciare, H. Cachier, and M. M. Abdelwahab. Ambient measurements of light-absorption by agricultural waste burning organic aerosols, J. Aerosol Sci., 40, 613-620 (2009)

19. Ronald G., W. McCarty, M. J. Suarez, et al. The Modern-Era Retrospective Analysis for Research and Applications, Version 2 (MERRA-2). J. Climate 30 (14): 5419-5454 (2017)

20. Streets, D. G., S. Gupta, S. T. Waldhoff, M. Q. Wang, T. C. Bond, and Y. Y. Bo. Black carbon emissions in China, Atmos. Environ., 35, 42814296 (2001)

21. Yang, Yuan Z.; Cai, Wen H.; and Yang, Jian. Evaluation of MODIS Land Surface Temperature Data to Estimate Near-Surface Air Temperature in Northeast China. Forestry and Natural Resources Faculty Publications. 15(2017)

22. Darmenov, A. and da Silva, A.. The Quick Fire Emissions Dataset (QFED) - Documentation of versions 2.1, 2.2 and 2.4, Technical Report, NASA (2015)
23. Yan P, Tang J, Huang J, Mao JT, Zhou XJ, Liu Q, Wang ZF, Zhou HG. The measurement of aerosol optical properties at a rural site in Northern China. Atmos Chem Phys 8:2229-2242 (2008) 